\title{
Diseases of Salivary Glands: Review
}

\author{
Alhan D Al-Moula \\ BDS, MSc (Assist Lect)
}

\author{
Department of Dental Basic Science \\ College of Dentistry, University of Mosul
}

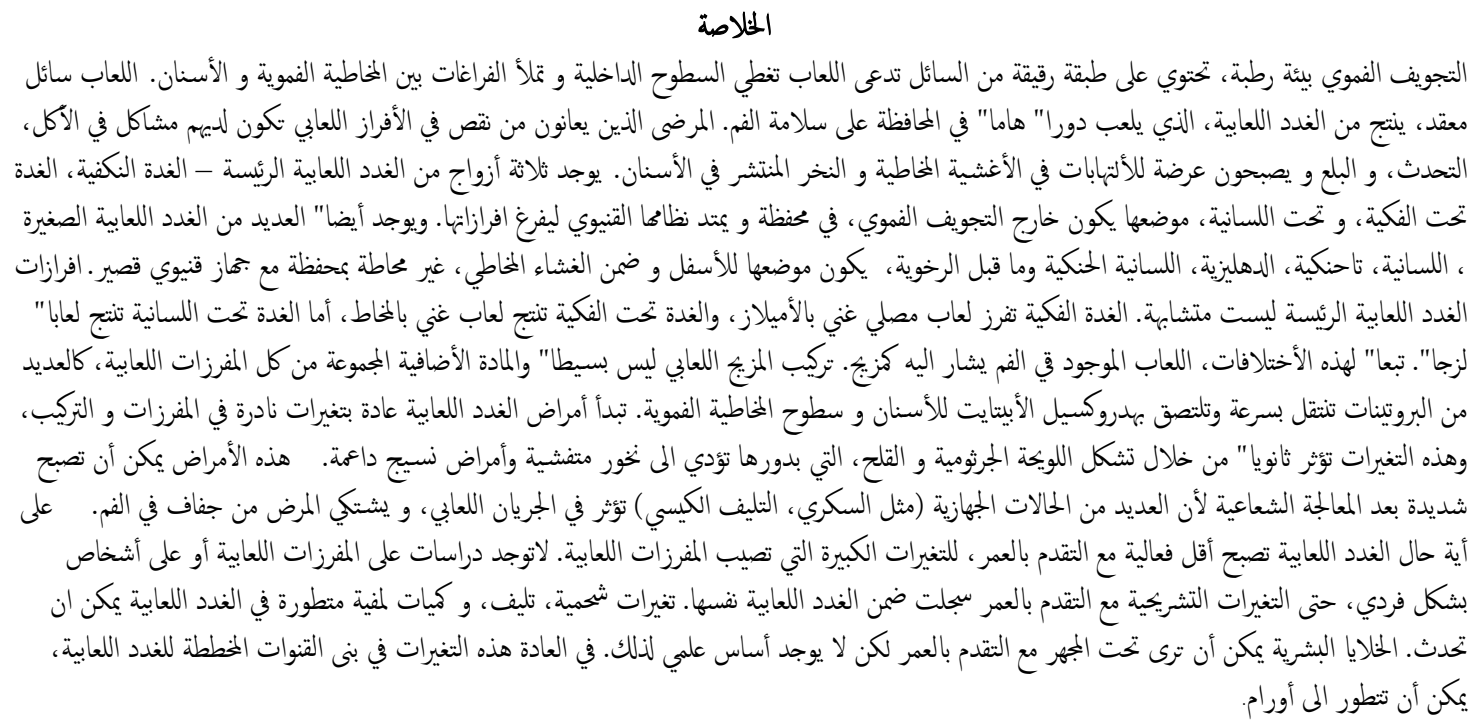

\section{ABSTRACT}

The oral cavity is a moist environment, a film of fluid called saliva constantly coats its inner surfaces and occupies the space between the lining oral mucosa and the teeth. Saliva is a complex fluid, produced by the salivary glands, whose important role is maintaining the wellbeing of the mouth. Patients with a deficiency of salivary secretion experience difficulty eating, speaking, swallowing as well as become prone to mucosal infections and rampant caries. In human there are three pairs of major encapsulated salivary glands - (parotid, submandibular, and sublingual). Located outside the oral cavity, with extended duct systems to discharge their secretion. There are also a multitude of smaller minor unencapsulated salivary glands. (labial, lingual, palatal, buccal, glossopalatine and retromolar). Located just below and within the mucous membranes, characterized by short duct systems. Secretion of each major salivary gland is not the same, the parotid glands secrete a rich amylase (watery serous saliva), whereas the submandibular gland produces mucinous saliva, and the sublingual gland produces viscous saliva. Because of these variations, saliva found in the mouth is referred to as mixed secretions, as many proteins are rapidly removed as they adhere to hydroxyl apatite of teeth and to the oral mucosal surfaces. Diseases of the salivary glands usually bring about changes in the rate of salivary secretion and composition. These changes have a secondary effect in that they lead to the formation of a plaque and calculus, which in turn has a direct bearing on the initiation of caries and periodontal disease. In addition to it, effect in the healthy condition of oral mucosal surfaces. There are many systemic conditions (e.g., diabetes, cystic fibrosis) affect salivary flows, a patient complaining of dry mouth must be thoroughly investigated. These diseases may become severe after therapeutic irradiation in and around the mouth. The salivary gland become less active with age while is problematic, because such a great variation exists in the secretion of saliva, but no longitudinal studies have thus far been reported. Even so, histological changes associated with age have been reported within the salivary glands. Fatty degenerative changes, fibrosis and the progressive accumulation of lymphocytes in the salivary glands are thought to occur. Oncocytes - epithelial cells that can be identified by there marked granularity and acidophilia under the light microscope, are thought to represent as age change, although their significance has not 
been established, beside accumulation of structurally altered mitochondria. Oncocytes are found in acini intercalated and striated ducts of salivary glands and which may give rise to neoplasms. The aim of this review is to provide athorough knowledge of anatomy, embryology and pathophysiology in necessary to treat patient appropriately. Examines the cause, diagnostic methodology, radiographic evaluation and management of a variety of salivary gland.

Keyword: Salivary gland, Histopathology of salivary glands, salivary gland disorders.

Al- Moula AD. Diseases of Salivary Glands: Review. Al-Rafidain Dent J. 2010; 10(2):214-230.

Received: 11/1/2009 Sent to Referees: 12/1/2009 Accepted for Publication:16/3/2009

INTRODUCTION

Anatomy of Salivary Glands (Figure 1):

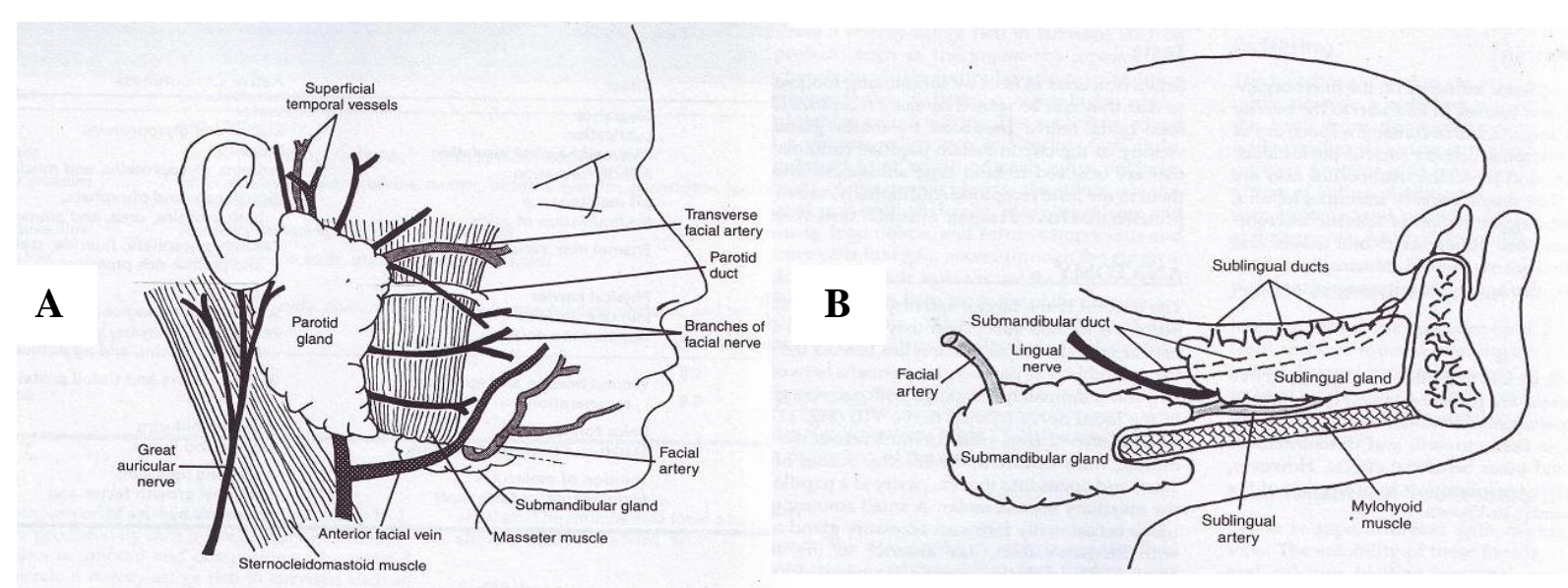

Figure (1): Anatomy of the major salivary glands. A, Parotid gland. B, Submandibular and sublingual glands (Snell R.S.)

\section{Parotid Gland:}

The parotid gland is the largest salivary glands, which lies superficial to the posterior aspect of the masseter muscle and the ascending ramus of the mandible. ${ }^{(1)}$ The deep part of the gland may extend forward between the medial pterygoid process. $^{(1)}$

The parotid gland is a lobulated mass surrounded by a connective tissue capsule, and enclosed by a dense fibrous capsule derived from the investing layer of deep cervical fascia. $^{(1)}$

Blood Supply:

The external carotid artery and its terminal branches: 1) posterior auricular arteries, 2) superficial temporal 3) and transverse facial arteries, while the veins drain into the retromandibular vein. ${ }^{(1)}$

Lymph drainage:

The lymph vessels drain into the parotid lymph nodes and the deep cervical lymph nodes. ${ }^{(1)}$

Nerve supply:
Parasympathetic secretomotor fibers from the inferior salivatory nucleus of the ninth cranial nerve supply the parotid gland. The nerve fibers pass to the otic ganglion via the tympanic branch of the ninth cranial nerve and the lesser petrosal nerve. Postganglionic parasympathetic fibers reach the parotid gland via the auriculotemporal nerve, which lies in contact with the deep surface of the gland. Postganglionic sympathetic fibers reach the gland as a plexus of nerves around the external carotid artery. ${ }^{(1)}$

\section{Submandibular Gland:}

The submandibular gland is located in the submandibular triangle of the neck, this triangle is formed by the anterior and posterior bellies of the diagastric muscles and the inferior border of the mandible. ${ }^{(1)}$ Blood supply:

The arteries are branches of the facial and lingual arteries. The veins drain into the facial and lingual veins.

Lymph drainage: 
The lymph vessels drain into the submandibular and deep cervical lymph nodes. ${ }^{(1)}$

\section{Nerve supply:}

Parasympathetic secretomotor supply from the superior salivatory nucleus of the seventh cranial nerve. The nerve fibers pass to the submandibular ganglion and other small ganglia close to the duct via the chorda tympani nerve and the lingual nerve. Postganglionic parasympathetic fibers reach the gland either directly or along the duct. Postganglionic sympathetic fibers reach the gland as a plexus of nerves around the facial and lingual arteries, from superior cervical ganglia. ${ }^{(1)}$

\section{Sublingual Gland:}

The sublingual gland is the smallest of the three main salivary glands, it lies beneath the mucous membrane of the floor of the mouth, close to the midline. The sublingual ducts are 8-20 in number and most of them open into the oral cavity on the summit of the sublingual fold, but a few may open into the submandibular duct. $^{(1)}$

Blood supply:

The gland is supplied by branches of the facial and lingual arteries. The veins drain into the facial and lingual veins. ${ }^{(1)}$

Lymph drainage:

The lymph vessels drain into the submandibular and deep cervical lymph nodes. ${ }^{(1)}$

\section{Nerve supply:}

Parasympathetic secretomotor supply from the superior salivatory nucleus of the facial nerve. The fibers pass to the submandibular ganglion via the chorda tympani nerve and the lingual nerve. Postganglionic parasympathetic fibers pass to the gland via the lingual nerve. Postganglionic sympathetic fibers reach the gland as a plexus of nerves around the facial and lingual arteries, from superior cervical ganglia. ${ }^{(1)}$

Histological feature of the Major Salivary Glands:

\section{Parotid Gland:}

In the parotid gland, the spherical secretory end pieces are all of serous type, and their pyramidally shaped acinar cells have a spherical, basally situated nucleus and surround a small, central lumen. The basal cytoplasm stains with basophilic dyes, and the secretory granules in the apical cytoplasms usually stain with acidophilic dyes. Fat cell spaces are often seen in sections of the parotid gland. ${ }^{(2)}$ Intercalated ducts are numerous and long in the parotid gland, they are lined with cuboidal epithelial cells and have lumina that are larger than those of acini. The striated ducts are numerous and appear as slightly acidophilic. The ducts consist of a simple columnar epithelium, with round, centrally placed nuclei, the lumina are larger relative to overall size of the ducts. ${ }^{(2)}$ Small ducts from various regions of the gland coalesce at the anterosuperior aspect of it to form (major Stensen's duct), which is about $1-3 \mathrm{~mm}$ in diameter and $6 \mathrm{~cm}$ in length, this duct opened intra orally adjacent to the upper molar tooth ${ }^{(2)}$.

\section{Submandibular Gland:}

The submandibular gland composed of a mixture of serous end pieces and mucous tubules capped with serous demilunes. Although the serous end pieces are similar in structure to those found in the parotid gland, with abundant secretory granules, a spherical nucleus and basophilic cytoplasm. The mucous secretory cells are filled with pale - staining secretory material, and little cytoplasm, while the nucleus is compressed against the basal cell membrane and contains densely stained chromatin. The intercalated and striated ducts are less numerous than those in the parotid gland, and its major duct known as Warton's duct passes forward in the sublingual space, and opened into the mouth behind lower incisor teeth. ${ }^{(3)}$

\section{Sublingual Gland:}

The sublingual gland is also a mixed gland, but mucous secretory cells predominate, while the mucous tubules and serous demilunes resemble those of the submandibular gland. The intercalated ducts are short and difficult to recognize. Whereas the Interlobular ducts are fewer in numbers than in the parotid or submandibular glands. ${ }^{(2)}$ (Figure 2). 


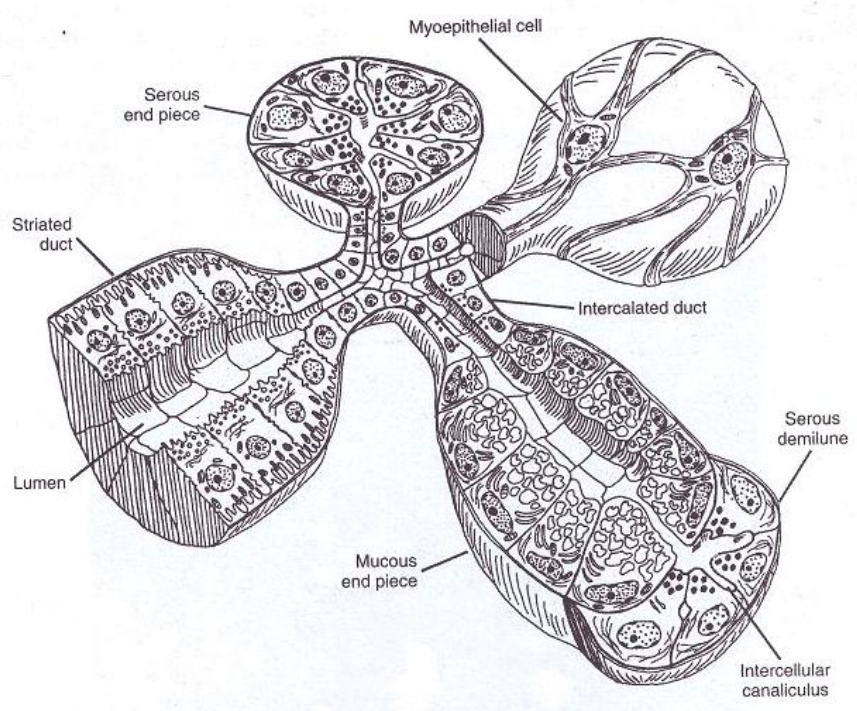

Figure (2): Architecture of salivary gland ducts, secretory end pieces and the main features of the paranchymal cells (Antonio N.)

The acinar ducts (Bartholin's ducts) of the sublingual glands are coalesce to form 8 20 ducts (Rivinus ducts), which are short and small in diameter and open directly into the anterior floor of the mouth. ${ }^{(3)}$

\section{Development of the Salivary Glands:}

All the salivary glands have the same plan of origin and development. ${ }^{(2)}$

The minor salivary glands begin to develop around the fortieth day in utero, whereas the larger major glands begin to develop slightly earlier. ${ }^{(2)}$ They arise at about the $7^{\text {th }}$ week as solid out growths of cells from the wall of the developing mouth, these cells grow into the underlying mesenchymes.

The epithelial buds branch repeatedly to form solid ducts, the ends of which round out to form solid ducts, the ends of which round out to form secretory acini. Later, the solid ducts and acini become canalized. The surrounding mesenchyme condenses to form the capsule and divides each gland into lobes or lobules. The ducts and acini of the parotid gland are derived from ectoderm, and those of the submandibular and sublingual glands are from endoderm. ${ }^{(2)}$

\section{Salivary gland weak point (clinical con- sideration):}

Parotid salivary gland and lesions of the facial nerve:

The terminal branches of the facial nerve lie between the superficial and deep part of gland and a benign parotid neoplasm rarely, if ever, causes facial palsy. A malignant tumor of the parotid gland is usually highly invasive and quickly involves the terminal branches of the facial nerve, causing unilateral facial paralysis. ${ }^{(1)}$

\section{Parotid gland infections:}

The parotid gland may become acutely inflamed as a result of retrograde bacterial infection from the mouth via the parotid duct. The gland may also become infected via the blood stream, as in mumps. The swollen gland extends behind the temporomandibular joint, is responsible for the pain in acute parotitis when eating. ${ }^{(1)}$

Submandibular salivary gland(calculus formation):

The submandibular salivary gland is a common site of calculus formation, while it is rare in the other salivary gland. The stone can be palpated in the duct, which 
lies below the mucous membrane of the floor of the mouth. ${ }^{(1)}$

\section{Sublingual salivary gland and cyst for- mation:}

The sublingual salivary gland, which lies beneath the sublingual fold of the floor of the mouth, opens into the mouth by numerous small ducts. Blockage of one of these duct is believed to be the cause of cysts under the tongue. ${ }^{(1)}$

\section{Developmental disturbances of salivary glands:}

\section{Xerostomia:}

Dry mouth or xerostomia, is a frequent clinical complaint. A loss of salivary function or a reduction in the volume of secreted saliva may lead to the sensation of oral dryness. Many drugs cause central or peripheral inhibition of salivary secretion and destruction of salivary gland tissue is another common cause of xerostomia. Loss of gland function occurs after radiation therapy for head and neck cancer, because the salivary glands often are included in the radiation fields. Chemotherapy for cancer or associated with bone marrow transplantation also may cause reduced salivary function. Autoimmune diseases, in particular Sjogren's syndrome, may cause progressive loss of salivary function from the invasion of lymphocytes into the gland and the destruction of epithelial cells. Treatment patient with xerostomia may include genetic modification of salivary gland cells to increase fluid and protein secretion. ${ }^{(2,4)}$

\section{Hyperplasia of the palatal glands:}

It is a non neoplastic enlargement of the minor salivary glands of the hard palate, with unknown cause, although there is some evidence to suggest that trauma plays a role. ${ }^{(5,6)}$

\section{Clinical features:}

The palate is the main site of involvement of this salivary gland hyperplasia. There is a male predominance and age ranges from 24-63 years. The clinical presentation is a unilateral swelling of the hard and/or soft palate. This lesion is asymptomatic, broad based and covered with intact mucosa of normal color and quality. ${ }^{(5,6)}$

3. Other disturbances are aplasia, atresia, aberrancy which are rarely caused ${ }^{(2)}$.

\section{Physiology of salivary glands:}

Secretion of saliva:

Daily secretion of saliva normally ranges between 800-1500 milliliters, with average value of 1000 milliliters, and contain two major types of protein secretion:

1. A serous secretion that contain ptyalin (an $\alpha$-amylase) which is an enzyme for digesting starches.

2. Mucus secretion that contains mucin for lubricating and for surface protective purposes.

Saliva has a ph between 6.0 and 7.0 a favorable range for the digestive action of ptyalin. ${ }^{(7)}$

\section{Secretion of ions in saliva:}

Saliva contains especially large quantities of potassium and bicarbonate ions. The concentration of both sodium and chloride ions are several times less than in saliva than in plasma. Under resting conditions; the concentration of sodium and chloride ions in the saliva are only about $15 \mathrm{mEq} / \mathrm{L}$ each and about $1 / 7$ to $1 / 10$ their concentration in plasma. Conversely, the concentration of potassium ions is about $30 \mathrm{mEq} / \mathrm{L}$, seven times as in plasma, while the concentration of bicarbonate ions is about $50-70 \mathrm{mEq} / \mathrm{L}$, about two to three times that of plasma. During maximal secretion; the salivary ionic concentration change considerably because the rate of formation of primary secretion by the acini can increase as much as 20 -fold. This acinar secretion then flows through the ducts as rapidly that the ductal reconditioning of the secretion is considerably reduced. The sodium chloride 
concentration rises only to one half of $2 / 3$ that of plasma, and the potassium concen- tration rises to only four times that of plasma. $^{(7,8)}$ Table (1):

Table (1) Daily saliva production by salivary gland

\begin{tabular}{ll}
\hline Submandibular gland & $70 \%$ \\
Parotid gland & $25 \%$ \\
Sublingual gland & $3-4 \%$ \\
Minor gland & Trace \\
\hline
\end{tabular}

\section{Function of saliva for oral hygiene:}

1- Helps wash away pathogenic bacteria as well as food particles that provide their metabolic support (Cleansing action).

2- Thiocyanate ions and anothers are several proteolytic enzymes -most important, lysozyme - that (a) attach the bacteria, (b) aid the thiocyanate ions in entering the bacteria where these ions in turn become bacteriocidal, and (c) digest food particles, thus helping further to remove the bacterial metabolic support.

3- Saliva often contain significant amounts of protein antibodies that can destroy oral bacteria. ${ }^{(7)}$ (antibacterial action).

Nervous regulation of salivary secretion:

The salivary glands are controlled mainly by parasympathetic nervous signals from the superior and inferior salivatory nuclei in the brain stem. Many taste stimuli, especially the sour taste (caused by acids), elicit copies secretion of saliva often 8 - 20 times the basal rate of secretion, also, certain tactile stimuli, such as the presence of smooth objects in the mouth (e.g., a pebble), cause marked salivation, where as rough objects cause less salivation and occasionally even inhibit salivation. Salivation can also be stimulated or inhibited by nervous signals arising in the salivatory nuclei from higher centers of the central nervous system. For instance, when a person smells or eats fa- vorite foods, salivation is greater than when disliked food is smelled or eaten. Salivation also occurs in response to reflexes originating in the stomach and upper small intestines. Sympathetic stimulation can also increase salivation a slight amount, much less so than does parasympathetic stimulation. The sympathetic nerves originate from the superior cervical ganglia and travel along the surface of the blood vessel walls to the salivary glands. A secondarily factor that also affects salivary secretion is the blood supply to the glands because secretion always requires adequate nutrients from the blood. The parasympathetic nerve signals that induce copious salivation also moderately dilate the blood vessels. In addition, salivation itself directly dilates the blood vessels, thus providing increased salivary glands nutrition as needed by the secretory cells. Part of this additional vasodilator effect is caused by kallikrein secreted by the activated salivary cells, which in turn acts as an enzyme to split one of the blood proteins, an alph 2 - globulin, to form bradykinin, a strong vasodilator. ${ }^{(7)}$

\section{Salivary gland radiology:}

1. Plain film radiographs:

The primary purpose of plain films in the assessment of salivary gland disease is to identify salivary stones (calculi) although only $80 \%$ to $85 \%$ of all stones are radiopaque and therefore visible radiographically Table (2). 
Table (2): Incidence of radiopaque stones

\begin{tabular}{ll}
\hline Submandibular gland & $70 \%$ \\
Parotid gland & $30 \%$ \\
\hline
\end{tabular}

A mandibular occlusal film is most useful technique to detect the calculi

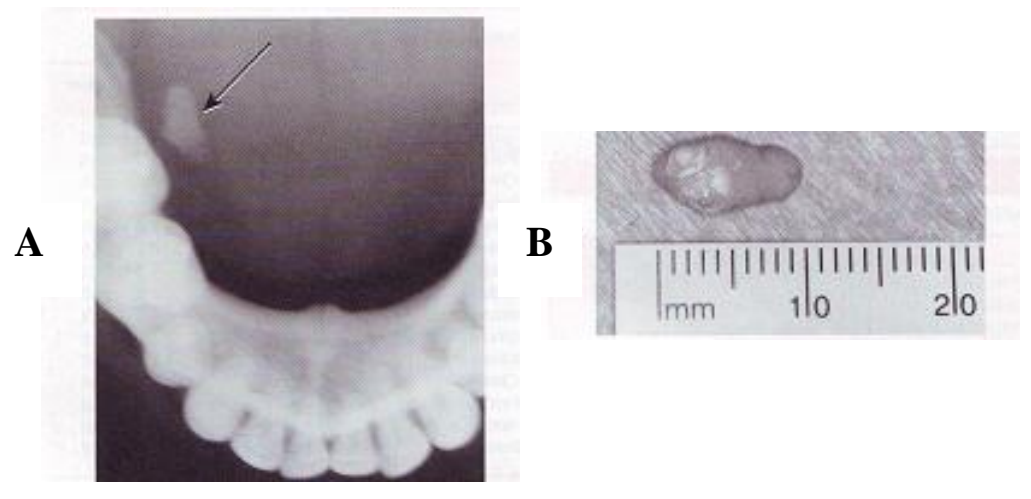

in the anterior floor of the mouth (Figure 3). ${ }^{(9)}$

Figure (3): A, Mandibular occlusal radiograph shows a radiopaque sialolith (arrow). B, Submandibular sialolith after intraoral removal is demonstrated.

Panoramic radiographs can reveal located submandibular stones (Figure 4). stones in the parotid gland and posteriorly

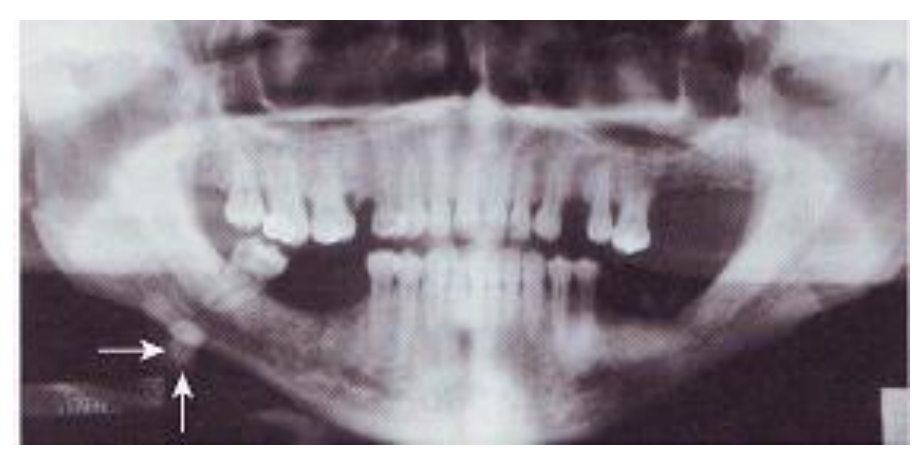

Figure (4): Panoramic radiograph demonstrates a right submandibular sialolith (arrows)

Periapical radiographs can show calculi in all salivary (major and minor) glands or their ducts, depending on film placement and in most instances, the radiographic image corresponds in size and shape to the actual stone. ${ }^{(9)}$

\section{Ultrasonography:}

Is relatively simple, with poor detail resolution. The primary role of ultrasonography is in the assessment of super- ficial structures to determine whether a mass lesion that is being evaluated is solid or cystic (fluid - filled) in nature. ${ }^{(9)}$

\section{Sialography:}

Sialography is indicated as an aid in the detection of radiopaque stones. Sialography is also useful in the assessment of the extent of destruction of the salivary duct or gland or both as a result of obstructive, inflammatory, traumatic and neoplas- 
tic disease, and also to detect any dilatation or narrowing or constriction of the duct $^{(9,10)}$.

Sialography is a technique in which the salivary duct cannulated with a plastic or metal catheter (Figure 5). It a dilation of the salivary duct secondary to epithelial atrophy as a result of repeated inflammatory or infections processes, with irregular narrowing caused by reparative fibrosis (i.e.," Sausage link" pattern) (Figure 6)

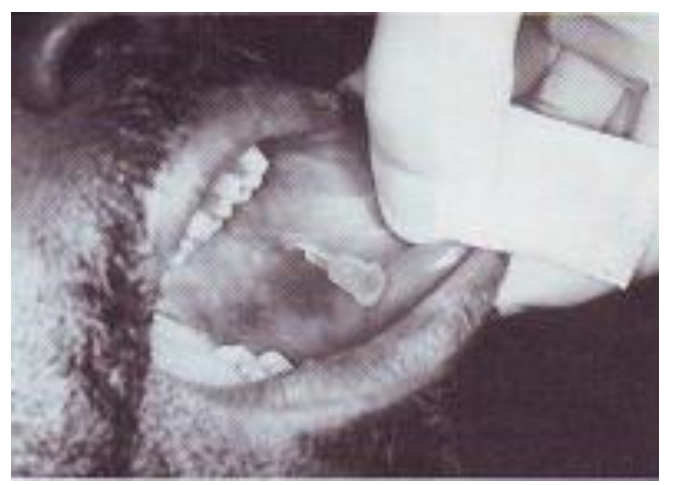

Figure (5): Cannulation of Stensen's duct with a plastic catheter

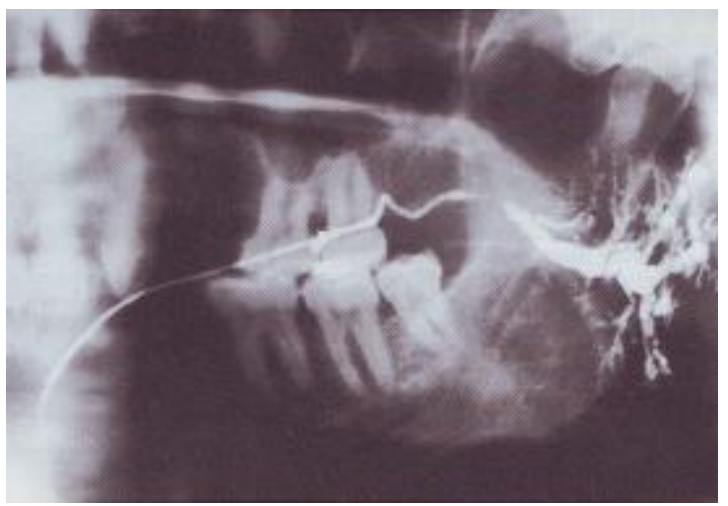

Figure (6): Sialogram of right parotid gland. The characteristics "Sausage link" appearance of the duct is demonstrated

Sialogram are specialized radiographic studies performed by oral and maxillofacial surgeons and some interventional radiologists trained in the technique ${ }^{(10)}$. The three contraindication of performing a sialogram are (1) acute salivary gland infections, (2) Patients with a history of iodine sensitivity, (3) before a thyroid gland study, because retained iodine in the vary gland or ducts may interfere with the thyroid scan. ${ }^{(9)}$

4. Computed tomography:

The use of computed tomography (CT) has been generally reserved for the assessment of mass lesions of the salivary glands. Although CT scanning results in radiation exposure to patients, it is less invasive than sialography and does not require the use of contrast material. ${ }^{(9)}$ (Figure 7) 


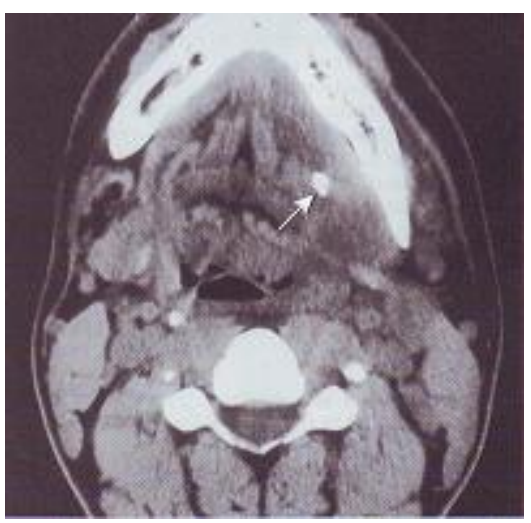

Figure (7): Computerized tomographic scan of the mandible and floor of mouth shows a posterior submandibular sialolith (arrow)

\section{Magnetic resonance imaging (MRI):}

Is superior to CT scanning in delineating the soft tissue detail of salivary gland lesions, specifically tumors, with no radiation exposure to the patient or the necessity of contrast enhancement. ${ }^{(91)}$

6. Salivary scintigraphy (radioactive isotope scanning):

The use of nuclear imaging in the form of radioactive isotope scanning, or salivary scintigraphy, allows a thorough evaluation of the salivary gland parenchyma, with respect to the presence of mass lesions and the function of the gland itself. This study uses a radioactive isotope [usually, technetium (TC) $99 \mathrm{~m}$ ] injected intravenously (IV), which is distributed throughout the body and taken up by a variety of tissues, including the salivary glands. ${ }^{(9)}$

\section{Sialochemistry:}

An examination of the electrolyte composition of the saliva. Principally the concentration of sodium and potassium, an elevated sodium concentration with a decreased potassium concentration may indicate an inflammatory sialadenitis. ${ }^{(9)}$

\section{Salivary gland biopsy:}

A salivary gland biopsy, either incisional or excisional, can be used to diagnose a tumor of one of the major salivary glands, but it is usually performed as an aid in the diagnosis of Sjogren syndrome (ss). The lower lip labial salivary gland biopsy has been shown to demonstrate certain characteristic histopathologic changes that are seen in the major gland in ss. The procedure is performed using local anesthesia, and approximately 10 minor salivary glands are removed for histological examination..$^{(3,9,11)}$

\section{Fine - needle aspiration biopsy:}

This procedure has a high accuracy rate for distinguishing between benign and malignant lesions in superficial locations. Fine - needle aspiration biopsy is performed using a syringe with a 20 -gauge or smaller needle. After local anesthesia the needle is advanced into the mass lesion, the plunger is activated to create a vacuum in the syringe, and the needle is moved back and forth throughout the mass, with pressure maintained on the plunger. The needle is withdrawn, and the cellular material with fluid are expelled onto a side and fixed for histological examination. ${ }^{(3,9)}$

\section{Salivary gland infections: Viral parotitis or mumps:}

Mumps is the most common viral infection which characterized by a painful, non erythematous swelling of one or both parotid glands that begins 2-3 weeks (incubation period) after exposure to the virus. This disease occurs most commonly in children between ages of 6-8 years and its signs and symptoms include preauricular 
pain and swelling, fever, chills and headache. Viral parotitis usually resolves in 512 days after its onset. Providing supportive and symptomatic care for fever, headache and malaise with antipyretic, analgesic and adequate hydration treats viral parotitis. ${ }^{(3,6,12)}$

\section{Sialadenitis:}

Inflammation of the salivary glands (sialadenitis) can arise from various and non infectious causes. The most bacterial infections arise as a result of ductal obstruction or decreased salivary flow. ${ }^{(13)}$

One of the more common causes of sialadenitis is the recent surgery (especially abdominal surgery), when acute parotitis (surgical mumps) may arise after such operation because the patient has been kept without food or fluids and received atrophy during the surgical procedure. ${ }^{(3,6,13)}$

\section{Acute bacterial sialadenitis:}

Histopathological feature:

Patient with acute sialadenitis, characterized by accumulation of neutrophilis within the ductal system and acini. ${ }^{(3,13,14)}$

\section{Chronic sialadenitis:}

Recurrent or persistent ductal obstruction (most commonly caused by sialoliths) can lead to chronic sialadentitis. Periodic swelling and pain occur within the affected gland, which usually developed at mealtime when salivary flow is stimulated. ${ }^{(15)}$

\section{Histopathological feature:}

Chronic sialadentitis is characterized by scattered or patchy infilteration of the salivary parenchyma by lymphocytes and plasma cells. Atrophy of the acini is common, as ductal dilatation and if associated with fibrosis, the term chronic sclerosing sialadentitis is used. ${ }^{(13)}$

\section{Subacute necrotizing sialadenitis:}

Is a recently recognized form of salivary inflammation that occurs most commonly in teenagers and young adults. The lesion usually involves the minor salivary glands of the hard or soft palate, presenting as a painful nodule that is covered by intact, erythematous mucosa. ${ }^{(13,16)}$

Histopathological feature:

Subacute necrotizing sialadenitis is characterized by a heavy mixed inflammatory infiltrate consisting of neutrophils, lymphocytes, histocytes and eosinophils. There is loss of most of acinar cells and many of remaining exhibit necrosis, while the ducts tend to be atrophic and do not show hyperplasia or squamous metaplasia. (13)

\section{Chelitis glandularis:}

Is a rare inflammatory condition of the minor salivary glands, with uncertain cause, although several etiologic factors have been suggested, including actinic damage, tobacco, syphilis, poor hygiene, and hereditary. ${ }^{(3,13,17)}$

\section{Clinical features:}

Chelitis glandularis characteristically occurs on the lower lip and the affected individuals experience swelling and reversion of lower lip as a result of hypertrophy and inflammation of the gland. The openings of the minor salivary ducts are inflamed and silated, beside pressure on glands may produce mucopurulent secretions from the ductal openings. The condition most often has been reported in middle - aged and older men, although cases have been described in women and children. However, some of the childhood cases may represent other enities such as exfoliative cheilitis. Chelitis glandularis has been classified into three types, based on the severity of the disease:

1. Simple.

2. Superficial suppurative (Baelz's) disease.

3. Deep suppourative (Chelitis glandulais apostematosa).

The latter two types represent progressive stages of the disease with bacterial involvement and are characterized by in- 
creasing inflammation, suppuration, ulceration, and swelling of the lip. ${ }^{(13,17)}$

\section{Sialolithiasis (salivary calculi; salivary} stones):

Sialoliths are calcified structures that develop within the salivary ductal system. They are believed to arise from deposition of calcium salts around a nidus of debris within the duct lumen and this debris may include inspissated mucus, bacteria, ductal epithelial cells, or foreign bodies. The cause of sialoliths is unclear, but their formation can be promoted by chronic sialadenitis and partial obstruction. Their development is not related to any systemic derangement in calcium and phosphorus metabolism. $^{(13,18,19)}$

The pathogenesis of salivary calculi progresses through a series of stages beginning with an abnormality in calcium metabolism and salt precipitation, with formation of organic and inorganic material to form a calcified mass. . ${ }^{(3,18,19)}$ The incidence of stone formation varies from $80 \%, 19 \%$ and $1 \%$ in submandibular, parotid and sublingual glands respectively ${ }^{(3)}$

A variety of factors contributes to the higher incidence of submandibular calculi. Salivary gland secretion contain water, electrolytes, urea, ammonia, glucose, fats, proteins and other substances. In general, parotid secretions are more concentrated than those of the other salivary glands and the main exception is the concentration of calcium, which is about twice as abundant in submandibular saliva as in parotid saliva. In addition, the alkaline ph of submandibular saliva may further support stone formation. Also the Wharton's duct of submandibular gland is the longest salivary duct, therefore saliva has a greater distance to travel before emptied into the oral cavity and it has two sharp curves in its course and, as well as the flow of saliva secretion occurs against the force of gravity. ${ }^{(3)}$ The occurrence of salivary gland stones is twice as common in men between age 30-50 years. But it is rare in children and the boys are more commonly affected than girls whereas the submandibular gland is most commonly affected. Multiple stone formation occurs in approximately $25 \%$ of patients. ${ }^{(3)}$

Histopathological feature:

On gross examination, sialoliths appear as hard masses that are round, oval, or cylindrical and typically yellow, although they may be white or yellowish brown. Submandibular stones tend to be larger than those of the parotid or minor glands. Sialoliths are usually solitary, although occasionally two or more stones may be discovered at surgery. Microscopically, the calcified mass exhibits concentric laminations that may surround anidus of a amorphous debris. The duct obstruction frequently is associated with an acute or chronic sialadenitis of the feeding gland..$^{(3,13,18)}$

The sublingual gland is examined by obstruction and bimanual palpation of the anterior third of the floor of the mouth.

The minor salivary glands are examined by observation and palpation of the mucosal surfaces of the lips, buccal mucosa, palate, and floor of the mouth.

Obstruction of the sublingual gland is unusual, but if it occurs, it is usually secondary to obstruction of Wharton's duct on the same side of the oral cavity. Although stone formation is rare in the sublingual and minor salivary glands, the treatment is simple excision of the stone and associated gland. ${ }^{(3)}$

\section{Other diseases that affect salivary gland:} Sjogren's syndrome:

Sjogren's syndrome (ss) is the expression of an autoimmune process that results principally in dry eyes (xerophthalmia) and dry mouth (xerostomia) owing to lymphocyte - mediated destruction of lacrimal and salivary gland parenchyma, in 
addition rheumatoid arthritis, may also be seen in this syndrome. ${ }^{(6)}$ So (ss) is a multisystem disease process with available presentation and classified into two types:

1. Primary (ss) (sicca syndrome); characterized by xerostomia (dry mouth) and (xerophthalmia) (dry eye).

2. Secondary (ss): composed of primary (ss), associated with connective tissue disorder, most commonly rheumatoid arthritis. Although the cause of (ss) is unknown, there appear to be a strong autoimmune influence, and it shows a female predilection of $9: 1$ with over $80 \%$ of affected individuals being females with a mean age of 50 years. $^{(3,6,20)}$

Generally, the first symptoms to appear are arthritis complaints, followed by ocular symptoms and late in the disease process, salivary gland symptoms. The involvement of the salivary and lacrimal glands results from a lymphocytic replacement of the normal glandular elements, therefore, xerostomia results from a decreased function of both the major and minor salivary glands, with the parotid gland being the most sensitive. ${ }^{(3,6)}$

The histopathologic changes seen in the minor glands are similar to those in the major (parotid) glands. Keratoconjuctivitis sicca is suggested by the patient's complaints and a schirmer's test for lacrimal flow. . $^{(3,4,6,11,20)}$

Diagnosis depends on the correlation between the patient history and laboratory data, clinical examination and assessment of salivary function. An important consideration concerns the clinical manifestation of xerostomia, although this is the main oral symptom and clinical sign in (ss), other considerations of dry mouth must be evaluated. In addition, major salivary gland enlargement is a feature of (ss) but may be episodic in nature and in some patients it may not be present at all. ${ }^{(3,6,11,20)}$

The prognosis of (ss): is complicated by an associated with malignant transformation to lymphoma. This may occur in approximately $6 \%-7 \%$ of cases and it is more common in those with only the sicca component of the syndrome. Less commonly observed is transformation of the epithelial component to undifferentiated carcinoma. Generally, the course for (ss) is one of chronicity, requiring long - term symptomatic management and careful follow-up by a dentist, ophthalmologist and rheumatologist. ${ }^{(3,6,20)}$

\section{Traumatic salivary gland injuries:}

Traumatic injuries, particularly lacerations, involving the salivary glands and their ducts may accompany a variety of facial injuries, including fractures. Injuries that occur in close proximity to one of the major salivary glands or ducts require careful evaluation. Facial lacerations may involve not only parotid gland and its ductal system, but also branches of the facial nerve and branches of major facial vessels. These structures require meticulous attention for appropriate diagnosis and prompt repair. Repair may include ductal anastomoses, in which the proximal and distal portions of the duct are identified, a plastic or metal catheter is placed as astent, and the duct is sutured over the stent. The catheter usually remains in place for $10-14$ days for epithelization of the duct to occur. Additionally, nerve anastomoses may be required and performed by placing epineural sutures, using magnification, to reapproximate the nerve stimps. The lacerations are closed in a usual layered fashion, after debridment of the soft tissue wounds to cleanse the site of entrapped particles, such as glass or dirt. Potential sequelae of trauma involving the major salivary glands include infections, facial paralysis, cutaneous salivary gland fistula, sialocele formation and duct obstruction as a result of scar formation, with eventual glandular atrophy and decreased function. 
The involved gland may eventually require surgical removal. ${ }^{(3,13)}$

(Reactive Lesions): Mucous retention and extravasation phenomena:

Mucocele:

Is a clinical term that include mucus extravasation phenomenon and mucus retention cyst. Because each has a distinctive pathogenesis and microscopy, they are considered separately.

Salivary ducts, especially those of the minor salivary glands, are occasionally traumatized, commonly by lip bitting, and severed beneath the surface mucosa. Subsequant saliva production may then extravasate beneath the surface mucosa into the soft tissues. Overtime, secretions accumulate within the tissues and produce a pseudocyst (without a true epithelial lining $)^{(2,3,8,21)}$ that contain thick, viscous saliva and these lesions are most common in the mucosa of the lower lip and known as mucoceles (Figure 8). The second most common site of mucocele formation is the buccal mucosa. Which results in an elevated, thinned, stretched overlying mucosa that appears as a vesicle filled with a clear or blue - grey mucus. The patient frequently relates a history of the lesion filling with fluid, rupture of fluid collection, and refilling of these lesions. Many stances of mucocele formation regress spontaneously without surgery, while in case of persistent or recurrent lesions, ferred treatment is required for excision of the mucocel and the associated minor salivary glands that contributed to its formation. Usually local anesthesia is administered via a mental nerve block, and an cision is made through the mucosa. ful dissection around the mucocele may permit its complete removal, however, in many cases the thin lining ruptures and decompresses the mucocele before removal. The regional associated minor salivary glands are removed and sent for thological evaluation. After surgical moval the recurrence rates of mucocele may be as high as $15 \%$ - 30\%, which sibly caused by incomplete removal or repeat trauma to the minor salivary glands..$^{(3,21)}$

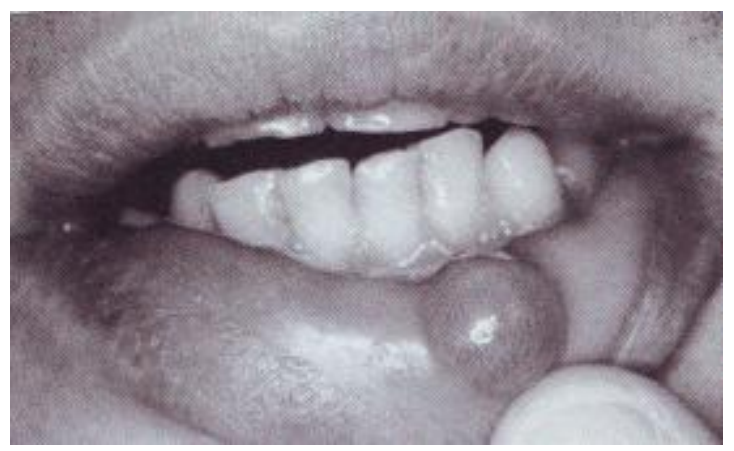

Figure (8): Mucocele of left lower lip

\section{Ranula:}

The most common lesion of the sublingual gland is the ranula, which may be considered a mucocele of the sublingual salivary gland. Ranulas result from either mucous retention in the sublingual gland ductal system or mucous extravasation as a result of ductal disruption and divided into simple and plunging types.
The simple ranula is confined to the area occupied by the sublingual gland in the sublingual space, superior to the mylohyoid muscle. The progression to a plunging ranula occurs when the lesion extend beyond the level of the mylohyoid muscle into the submandibular space. Ranulas may reach a larger size than mucoceles, because their overlying mucosa is thicker 
and the trauma that would cause their repture is less likely in the floor of the mouth. As a result a plunging ranula has the potential to extend into the neck and compromise the airway, resulting in a medical emergency. ${ }^{(3,13,6,22-25)}$

\section{Sialocyst (salivary duct cyst):}

The salivary duct cyst is an epithelium - lined cavity that arises from salivary gland tissue and unlike the more common mucocele, it is a true cyst because it is lined by epithelium. The cause of such cysts is uncertain, but some cases may represent ductal dilation secondary to ductal obstruction (e.g., mucus plug) which creates increased intraluminal pressure. Some authors refer to such lesions as mucus retention cyst, while other cases appear separate from the adjacent normal salivary ducts. ${ }^{(13)}$

\section{Clinical features:}

Salivary duct cysts usually occur in adults and can arise with either the major or minor glands. Cysts of the major glands are most common within the parotid gland, presenting as slowly growing, asymptomatic swellings. Intraoral cysts can occur at any minor gland site, but most frequently they develop in the floor of the mouth, buccal mucosa, and lips. They are often look like mucoceles, and characterized by soft, fluctuant swelling that may appear bluish, depending on the depth of the cyst below the surface and some cysts may feel relatively firm to palpation. Cysts in the floor of the mouth often arise adjacent to the submandibular duct and sometimes have an amber color. ${ }^{(13)}$

\section{Sialorrhea:}

Sialorrhea, or excessive salivation, is an uncommon condition that has various causes. Minor sialorrhea may result from local irritations, such as apthous ulcers or ill - fitting dentures. Patients with new dentures often experience excess saliva production until they become accustomed to the prosthesis. Sialorrhea is a well known clinical feature of rabies and heavy metal poisoning, as well as a consequences of certain medications, such as lithium and cholinergic agonists. ${ }^{(13)}$

\section{Clinical features:}

The excess saliva production typically produce drooling and choking, which may cause social embarrassment. In children with mental retardation or cerebral palsy, the uncontrolled salivary flow may lead to macerated sores around the mouth, chin and neck that can become secondarily infected.

An interesting type of supersalivation of unknown cause has been tremed idiopathic paroxysmal sialorrhea. Individuals with this condition experience short episodes of excessive salivation lasting from 2 - 5 minutes, and associated with a prodram of nausea or epigastric pain. ${ }^{(13)}$

\section{Salivary gland tumor:}

\section{A- Benign salivary gland tumors:}

1. Benign mixed tumor or pleomorphic adenoma (Figure 9):

Is the most common salivary gland tumor with mean age of occurance 45 years, and a male to female ratio of $3: 2$. In the major glands, the parotid gland is involved in over $80 \%$ of cases, in the minor glands the most common intraoral site is the palate. Pleomorphic adenomas are usually slow - growing, painless masses with two cell type; 1) the ductal epithelial cell and 2) the myoepithelial cell, which may differentiate along a variety of cell lines pleomorphic mean many form. The treatment involves complete surgical excision with a margin of normal involved tissue. $^{(3,13,26,27)}$ 


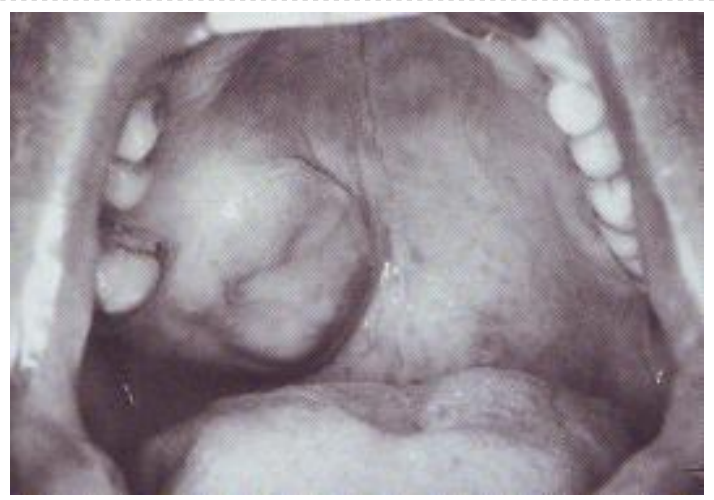

Figure (9): Pleomorphic adenoma of the right palate

2. Papillary cyst adenoma lymphoma (Warthin's tumor):

Almost exclusively affects the parotid gland and specifically its tail with peak incidence in the sixth decade of life and a male to female ratio $7: 1$, the lesion of Warthin's tumor presents as a slow growing - soft, painless mass. Which is believed to be caused by entrapped salivary epithelial rests within developing lymph nodes. The histopathology shows an epithelial component in a papillary pattern and a lymphoid component with germinal center. $^{(3,28,29)}$

\section{Monomorphic adenoma:}

Is an uncommon solitary lesion composed of one cell type, affecting predominately the upper lip minor glands (basal cell adenoma). The mean age of occurrence is 61 years and the lesion usually presents as a symptomatic, freely movable mass. The histopathology reveals an encapsulated lesion composed of one type (monomorphic) of salivary ductal epithelial cell. ${ }^{(3,6,13)}$

\section{B-Malignant salivary gland tumors:}

\section{Mucoepidermoid carcinoma:}

The mucoepidermoid carcinoma is the most common malignant salivary gland tumor. It comprises $10 \%$ of major gland tumors (mostly parotid gland) and $20 \%$ of minor gland tumors (mostly palate). This lesion may occur at any age, but the mean age is 45 years. The male to female ratio is
3:2. The clinical presentation is a submucosal mass that may be painful or ulcerated with a bluish tinge because of mucous contained within the lesion. An intraosseous form of mucoepidermoid carcinoma may present as a multilocular radiolucency of the posterior mandible. The histopathology shows three cell types (1) mucous, (2) epidermoid, and (3) intermediate (clear) cells. The proportion of each cell type helps to grade the mucoepidermoid carcinoma as a high - inter mediate or low grade lesions. The higher grade, the more predominance of epidermoid cells and pleomorphism, lack of mucous cells and cystic areas, and over all more aggressive behavior. ${ }^{(11,30-32)}$

2. Polymorphous low - grade adenocarcinoma:

Is the second most common intraoral salivary gland malignancy, which was first described in 1983 and before its identification, many cases were probably misdiagnosed as adenoid cystic carcinoma. The most common site is the junction of the hard and soft palates with male to female ratio of 3:1, with a mean age of 56 years. These tumors present as slow - growing, asymptomatic masses that may be ulcerated. The histopathology shows many cell shapes and patterns (polymorphous). $\mathrm{Pa}-$ tients experience an infiltrative proliferation of ductal epithelial cells in an "Indian file" pattern. This lesion shows a predilec- 
tion for invasion of surrounding nerves. $^{(3,13,30,33,34)}$

\section{Adenoid cystic carcinoma:}

Is the third most common intraoral salivary gland malignancy, with a mean age of 53 years and a male to female ratio of 3:2. Approximately $50 \%$ of these tumors occur in the parotid gland, whereas the other $50 \%$ occur in the minor glands of the palate. These present as slow growing, non ulcerated masses, with an associated chronic dull pain. Occasionally, parotid lesions may result in facial paralysis as a result of facial nerve involvement. The histopathology demonstrates an infiltrative proliferation of basaloid cells arranged distant in a "cribriform" (Swiss cheese) pattern. As seen in the polymorphous low - grade adenocarcinoma, there may be perineural invasion. ${ }^{(3)}$ Because the tumor is prone to late recurrence and metastasis, as well as 5 years survival rate has little significance and does not equate to a cure, this rate may be as high as $70 \%$, but it continues to decrease overtime and by 20 years, only $20 \%$ of patients are still a live. Tumors with a solid histopathologic pattern are associated with a worse out look than those with a cribriform or tubular arrangement. With respect to site, the prognosis is poorest for tumors arising in the maxillary sinus and submandibular gland. Most studies have shown than microscopic identification of perineural invasion has little effect on the prognosis. Death usually results from local recurrence or distant metastasis, which commonly occurs to the lungs and bones, while tumors of the palate or maxillary sinus eventually may invade up ward to the base of the brain. ${ }^{(13)}$

\section{REFERENCES}

1. Snell RS. Clinical Anatomy for Medical Students. $7^{\text {th }}$ edition. SMHS Washington. 2004; Pp. 773 - 788.

2. Antonio N. Ten Cate's Oral Histology,
Development, Structure and Function. $6^{\text {th }}$ edition. 2003; Pp. $299-328$.

3. Larry J P, Edward E, James R. H. Diagnosis and Management of Salivary Gland Disorders Contemporary Oral and Maxillofacial Surgery, $4^{\text {th }}$ edition. Mosby. 2003; Pp. 434 - 455.

4. Vanderwaal IE. Diseases of the Salivary Glands. J Oral Maxillofacial Surg. 1997; 34: 15.

5. Arafat A, Brannon RB, Ellis GL. Adenomatoid hyperplasia of mucous salivary glands. Oral Surg Oral Med Oral Path. 1981; 52: 51 - 55.

6. Joseph AR, James JS, Richard CKJ, Fred C. Oral Pathology (Clinical Pathologic Correlation), $4^{\text {th }}$ edition. WD Saunders, 2003; Pp. 183 - 217.

7. Arthur CG, John EH. Secretory Functions of the Alimentary Tract: Text Book of Medical Physiology. $11^{\text {th }}$ edition. Vol. 2, 2006; Pp. 793 - 806.

8. Tandler B, Gresik EW, Nagato T, Philips CJ. Secretion by striated ducts of mammalian major salivary gland: review from histological, functional and evolutionary prespective. Anat Rec. 2001; 264: 121.

9. Noyek AM. Head and Neck Radiology. Gower medical publishing. London. $3^{\text {rd }}$ edition. $1991 ; 312-324$.

10. Stephens LC, Schulthesis TE, Price $\mathrm{RE}$, et al. Radiation apoptosis of serous acinar cells of salivary and lacrimal glands. Cancer. 1991; 67: 1539 1543.

11. Abaza N. The role of labial salivary gland biopsy in the diagnosis of Sjogren's syndrome: report of three cases. J Oral Maxillofacial Surg. 1993; 51(5): 574.

12. Goldberg MH, Bevilacqua RG Infections of the salivary glands. J Oral Maxillofac Surg. 1995; 7: 423.

13. Brad W N, Douglas DD, Carl MA, Jerry E.: Oral and Maxillofacial Pathology. $2^{\text {nd }}$ edition. 2002; Pp. $675-$ 679.

14. Blitzer A. Inflammatory and obstructive disorders of salivary glands. $J$ Dent Res. 1987; 66 (Supp 1): 675 679.

15. Koudelka BM. Obstructive Disorders: Ellis GL, Auclair PL, Gnepp DR (eds). Surgical pathology of the salivary 
glands. WB Saunders, Philadelphia. 1991; Pp. 95 - 96.

16. Fowler CB, Brannon RB. Subacute necrotizing sialadenitis: report of 7 cases and a review of the literature. Oral Surg Oral Med Oral Pathol. 2000; 89: 600 - 609.

17. Cohen DM, Green JG, Dickmann SL Concurrent anomalies: cheilitis glandularis and double lip: report of a case. Oral Surg Oral med Oral Pathol. 1988; 66: 397 - 399.

18. Narang $R$ and Dixon RA. Surgical management of submandibular sialadenitis and sialolithiasis. Oral Surg Oral Med Oral Pathol. 1977; 43: 201 $-210$.

19. Yoshimura Y, Morishita T and Sugihara T. Salivary gland functions after sialothiasis: scintigraphic examination of submandibular glands with tepertechnetate. J Oral Maxillofac Surg. 1989; 47: $704-710$.

20. Linvall AM and Jonsson R. The salivary gland component of Sjogren's syndrome: an evaluation of diagnosis methods. Oral Surg Oral Med Oral Pathol. 1986; 62: 32 - 42.

21. Jensen JL. Superficial mucoceles of the oral mucosa. Am J Dermatopathol. 1990; 12: 88 - 92 .

22. Baurmash HD. Marsupialization for treatment of oral ranula: a second look at the procedure. J Oral Maxillofac Surg. 1992; 50: 1274.

23. Galloway RH, Gross PD, Thompson $\mathrm{SH}$, et al. Pathogenesis and treatment of ranula: report of three cases: J Oral Maxillofac Surg. 1989; 47: 299 - 302.

24. McClatchey KD, Appelblatt NH, Zarbo RJ. Plunging ranula. Oral Surg Oral Med Oral Pathol. 1984; 57: 408 $-412$.

25. Yoshimura Y. A comparison of three methods used for treatment of ranula. J Oral Maxillofac Surg. 1995; 53: 280.

26. Chau MY, Radden BG. A clinical pathological study of 53 intraoral pleomorphic adenomas. J Oral Maxillofac Surg. 1989; 18: 158 - 162.

27. Kanazawa H, Faruya T, Watanabe Te. Plasma cytoid myoepitheloma of the palate. J Oral Maxillofac Surg. 1999; 57: $857-860$.

28. Kotwall CA. Smoking as an etiologic factor in the development of Warthin's tumor of the parotid gland. Am J Surg. 1992; 164: 646 - 647.

29. Vanderwaal IE, Davids JJ, Vanderwaal I Extra parotid Warthin's tumors - report of 10 cases. J Oral Maxillofac Surg. 1993; 31: 43 - 44.

30. Caslle JT, Thompson LR, Frommelt RA.: Polymorphous low grade adenocarcinoma. A clinicopathologic study of 164 cases. Cancer. 1999; 86: 207 219.

31. Ellis GL, Auclair PL, Gnepp DR.: Surgical pathology of the salivary glands, (Clinical Pathologic Correlation), $1^{\text {st }}$ edition. WB Saunders. 1991; Pp. 45-47.

32. Stene T, Koppang HS Intraoral adenocarcinomas. J Oral Pathol. 1981; 10: $216-225$.

33. Evan HL. Mucoepidermoid carcinoma of salivary glands: a study of 69 cases with special attention to histologic grading. Am J Pathol. 1984; 81: 696 701.

34. Vincent SD, Hammond HL, Finkelstein MW Clinical and therapeutic features of polymorphous low - grade adenocarcinoma. Oral Surg Oral Med Oral Pathol. 1994; 77: 41 - 47. 